\title{
CONTRIBUCIÓN AL CONOCIMIENTO ARQUEOLÓGICO A TRAVÉS DEL ANÁLISIS DE COLECCIONES MUSEOLÓGICAS
}

Bárbara Balesta*

Nora.Zagorodny*

\begin{abstract}
BALESTA, B; ZAGORODNY, N. Contribución al conocimiento arqueológico a través del análisis de colecciones museológicas. Rev. do Museu de Arqueologia e Etnologia, São Paulo, 8: 235-240, 1998.
\end{abstract}

RESUMO: $O$ artigo refere-se à história e peculiaridades da coleção Benjamin Muñiz Barreto. Esta coleção está localizada no Museu de La Plata (Argentina). $\mathrm{O}$ objetivo das autoras é revalorizar a informação proveniente de coleções do Museu. A metodologia aplicada apoia-se num referencial cognitivista e estabelece abordagens tecnológicas e simbólicas.

UNITERMOS: Revalorização - Coleção - Museu - Cognitivismo.

\section{Introducción}

El objetivo de este trabajo consiste en la revalorización de la información proveniente del estudio de colecciones públicas y/o privadas, a través del comentario del trabajo de las autoras sobre materiales funerarios de colección.

Según el desarrollo de la historia de la Antropología, las colecciones museológicas sirvieron, en el pasado, para contribuir al conocimiento del origen y desarrollo de los hombres y grupos humanos a través de estudios descriptivos y comparativos sobre los objetos materiales que las constituían. Con el correr de los años, los depósitos de los museos fueron abandonados, en calidad de reservorios destinados a la mera acumulación de dichos objetos, considerando que ya se había "ex-

(*) Laboratorio de Análisis Cerámico. Facultad de Ciencias Naturales y Museo. Universidad Nacional de La Plata. La Plata, Argentina. traído" de ellos todo el saber que podían proporcionar. Actualmente esta tendencia se está revirtiendo, ya que se piensa que los mismos materiales, a la luz de otras metodologías de abordaje pueden proporcionar nuevas y crecientes fuentes de conocimiento.

En tal sentido, en el presente se comentan la historia y características particulares de la Colección Benjamín Muñiz Barreto del Museo de La Plata y los trabajos que sobre ella se llevan a cabo por parte del equipo de investigación del Laboratorio de Análisis Cerámico de la Facultad de Ciencias Naturales (UNLP), constituyendo de este modo un aporte al conocimiento antropológico a partir de la revalorización del estudio del patrimonio alojado en dicha institución.

A fin de establecer el tipo de información que se puede extraer del estudio de una colección resulta importante tener en cuenta ciertas cuestiones que se refieren al modo en que la misma llegó a formar parte del patrimonio de una institución. Resulta relevante responder a las preguntas de cómo y cuándo se formó la colección, quién o quiénes 
fueron los encargados de su recuperación - tanto en lo que atañe al hallazgo y/o excavaciones como a su posterior ingreso institucional -, si existe algún registro de las operaciones involucradas en dicha recuperación, etc.

\section{Historia y características de la colección Muñiz Barreto}

La Colección Benjamín Muñiz Barreto tiene una historia muy particular. Debe su nombre al estanciero homónimo de origen brasileño, quien radicado en la provincia de Buenos Aires, dedicó su vida y fortuna a comprar y recuperar tesoros arqueológicos.

Una parte de las alrededor de doce mil piezas que componen la Colección y que corresponden a la sección peruana fueron adquiridas por este estanciero en el extranjero. Pero la porción mayor de la misma (aproximadamente diez mil novecientas), es el producto de tareas sistemáticas de excavación subvencionadas por él. El interés de Barreto como coleccionista de antigüedades fue dirigido a la obtención de piezas completas y de carácter especial en cuanto a la dedicación invertida en su manufactura y decoración. Esto marcó los comienzos de este conjunto arqueológico. En tal sentido, las expediciones que financió se dedicaron a la recuperación de objetos provenientes de unidades de entierro - tanto aisladas como aglutinadas en cementerios indígenas -, que cumplían en mayor medida con tales requisitos.

Esta vasta colección es el resultado de las labores de investigación de campo, de excavación de tumbas y relevamiento topográfico de sitios de ocupación indígena precolombina, realizadas entre los años 1919 y 1930 en el Noroeste argentino (provincias de Jujuy, Tucumán y Catamarca). Estas labores fueron iniciadas en 1919 por Don Carlos Schuel a quien se le unió en 1920 en Jujuy el Ing. Wladimiro Weisser, quien posteriormente lo reemplazó en forma definitiva. Este era un alemán nacionalizado argentino que fue dirigido en su tarea por el prestigioso científico Salvador Debenedetti, quien también estuvo a cargo de la clasificación y catalogación de los materiales y en varias ocasiones se trasladó al campo para supervisar las tareas de excavación. A las órdenes del Ing. Weisser trabajó un equipo de profesionales ocupados en distintas funciones como la restauración de piezas, dibujo, fotografía, etc, entre los cuales se destacan los Sres. Federico Wolters, F. Murr, A. P. Peperniceck y Antonio Bernarsich, entre otros. A la muerte de Weisser, en 1926, la dirección de los trabajos recayó en Federico Wolters.

Durante los doce años de intensa labor se estudiaron alrededor de medio centenar de sitios de ocupación indígena en diversas localidades del NOA. Esto representó la posibilidad de contar con una muestra exhaustiva de una vasta región cultural, el NOA, abarcando a su vez un lapso temporal que va desde antes de los comienzos de la era cristiana hasta el perído hispano-indígena.

La exhaustividad con que se registraron los trabajos queda atestiguada por el hecho de que si bien los intereses de Barreto se referían a piezas funerarias completas y finas, los materiales fueron recogidos en su totalidad; salvo que se deshicieran como en el caso de muchas urnas. No obstante, en estos casos, la existencia y características de las piezas eran fielmente registradas. A pesar de las precisas instrucciones de Barreto sobre la excavación de tumbas, el interés de Weisser determinó que se realizaran prospecciones y planos de sitios de habitación como el caso de la Loma de los Antiguos en la localidad de Asampay, Prov. de Catamarca (Balesta y Zagorodny 1997).

Cabe señalar que el registro documental mereció el elogio y la admiración de grandes personalidades científicas de la época, tanto nacionales como extranjeras, tales los casos de Paul Rivet, Erland Nordenskiold, Charles Diehl, etc. Por otra parte, los materiales de esta colección fueron objeto de importantes obras de investigadores como Salvador Debenedetti, Fernando Márquez Miranda y Alberto Rex González.

La gran cantidad de piezas acumuladas a lo largo de una década, llevó a Barreto a la instalación de un museo en la ciudad de Buenos Aires con una serie de salas de exposición y lugar de estudio para sus investigadores.

En 1931 la Colección fue depositada en el Museo de La Plata, momento en que Muñiz Barreto la ofreció en venta a dicha institución. El proceso de compra por parte del gobierno fue arduo y complejo, efectivizándose la misma el 2 de septiembre de 1933, días después de la muerte de su propietario.

Actualmente, la catalogación sigue los lineamientos fijados por Debenedetti. A cada pieza del ajuar fúnebre le corrrespondieron tres números de identificación: uno colocado en el momento del 
BALESTA, B; ZAGORODNY, N. Contribución al conocimiento arqueológico a través del análisis de colecciones museológicas. Rev. do Museu de Arqueologia e Etnologia, São Paulo, 8: 235-240, 1998.

hallazgo, otro al fin de cada período de labor y el tercero en el momento de la catalogación final. De esta manera resulta sencillo reunir los materiales correspondientes a cada hallazgo. No obstante, en algunos pocos casos se han comprobado errores de catalogación o transposición de piezas; esto ocurre en particular en la décima expedición y en menor medida en las anteriores.

\section{Aspectos metodológicos}

La investigación que vienen desarrollando las autoras con el universo descripto tiene como objetivo la recuperación de las operaciones cognitivas involucradas en la producción de la alfarería funeraria. Los enfoques de abordaje son dos: el tecnológico y el simbólico, que operan en forma independiente y complementaria.

Previo al desarrollo de la metodología empleada cabe aclarar que el trabajo con una colección museológica presenta ventajas y restricciones de distinto tipo que son la consecuencia de los modos particulares de conformación de la misma.

El caso que nos ocupa reviste características excepcionales que si bien ya se han adelantado pueden sintetizarse en los siguientes puntos:

- conocimiento preciso de la procedencia del material

- importante volumen numérico de la porción argentina (10900 objetos)

- excelente nivel de conservación de las piezas

- existencia de soporte documental literario, gráfico y fotográfico

En cuanto a las restricciones detectadas durante el trabajo se pueden citar las referentes al soporte documental y aquéllas que afectan al material recuperado en excavaciones. En el primer caso cabe observar:

- impedimentos en la lectura, en cuanto a la visibilidad de la caligrafía de los diarios de campo de los Ing. Weisser y Wolters;

- obstáculos en la interpretación del discurso elaborado por los autores en función de un lenguaje propio de otra época y una sintaxis a veces imprecisa, ya que aquéllos eran de origen alemán;

- las exigencias en cuanto al manejo del lenguaje científico diferían de las actuales, enfrentándonos al problema de la ambigüedad del significado de la terminología utilizada.
El primer planteo se subsanó transcribiendo el material documental a nivel gráfico y literario. El segundo y tercero se optimizaron aislando los términos ambiguos y buscando las similitudes y variaciones de los mismos en sus diferentes contextos de utilización.

Además, en cuanto a los términos usados para designar y describir objetos de ajuar se procedió a su contrastación con los materiales ingresados e inventariados.

Las restricciones que afectan al material recuperado en las excavaciones se relacionan con el largo período que lleva el material en depósito, el cual no se encuentra en las condiciones óptimas requeridas para su conservación. Por este motivo hay piezas que han sufrido deterioro, por ejemplo fragmentación parcial o total.

Los problemas referentes al producto de aquellas fragmentaciones han derivado en dificultades para adscribir los fragmentos a sus piezas de origen, ya que los mismos han sufrido una dispersión involuntaria con la consecuente pérdida de su referencia real.

Teniendo en cuenta que se está trabajando con material perteneciente al patrimonio de una institución debemos asegurarnos, cuando trabajamos con material fragmentario, de que los fragmentos muestreados pertenezcan a piezas no solamente representativas, sino también originalmente incompletas, puesto que varias de las tareas de análisis tecnológico son de carácter destructivo.

Otro obstáculo existente con respecto al material fragmentario - en cuanto al análisis simbólico - se plantea en la imposibilidad de recuperar el total del área decorada de cada pieza, que permita apreciar el modo en que se configuraron y se combinaron las unidades de decoración.

Una importante falencia que presenta la Colección es el hecho de que los restos humanos correspondientes a cada inhumación fueron redepositados en sus lugares de origen por los responsables de las expediciones. Esto nos ha privado de contar con una importante información acerca de las características físicas de los grupos que habitaron esta zona en términos de determinaciones raciales, sexuales, etarias, patológicas, nutricionales, prácticas de deformación craneana, mecanismos de dinámica poblacional, determinaciones genéticas y a través de éstas sus vinculaciones parentales, etc. 
BALESTA, B; ZAGORODNY, N. Contribución al conocimiento arqueológico a través del análisis de colecciones museológicas. Rev. do Museu de Arqueologia e Etnologia, São Paulo, 8: 235-240, 1998.

\section{Construcción de herramientas analíticas}

Una de las tareas inherentes al trabajo con colecciones consiste en la clasificación de los materiales que las componen. La misma puede basarse en tipologías tradicionales, o consistir como en nuestro caso, en la confección de herramientas donde se aplican metodologías más completas y complejas. Esta aplicación se materializa en nuestra propuesta de construcción de grupos de referencia que expresan, a través de un conjunto de objetos, un criterio descriptivo o la combinación de varios de ellos.

Los grupos de referencia son construcciones subjetivas y pautadas que funcionan como herramientas analíticas que permiten establecer comparaciones entre diferentes universos de estudio. Los grupos se constituyen como "entidades dinámicas" variando en función de los intereses que guían los distintos momentos de la investigación para la cual se construyen (Zagorodny y Balesta 1997).

Pueden existir tantos grupos de referencia como niveles de análisis se recorten sobre el universo de estudio. Para realizar este recorte se seleccionan e interrelacionan diferentes criterios. Cada criterio toma en cuenta distintas variables. Un punto de partida viable puede consistir en trabajar con los criterios de: morfología, manufactura, decoración y evidencias de utilización. Estos criterios han sido trabajados desde los puntos de vista tecnológico y comunicacional, tanto sobre piezas completas como sobre material fragmentario.

Las variables serían, por ejemplo, dentro del criterio morfológico las de forma y tamaño; dentro del criterio de manufactura las de acabado de superficie, cocción, evidencias de restauración, etc.

El producto final de la construcción de grupos consistió en la generación de subconjuntos dentro de la Colección que representan el rango de variación de cada criterio seleccionado.

La eventualidad de que una colección (como la que aquí se comenta) cuente con corpus documentales permite realizar otro tipo de recortes sobre el universo de estudio. Entendemos por corpus documental a todo tipo de soporte, ya sea literario, gráfico o medial que proporcione información adicional de un objeto o colección arqueológica, localización, condiciones de hallazgo, diarios de viaje, documentación epistolar, descripciones, dibujos, fotografías, planos, croquis, catálogos, etc.
En nuestro caso la combinación de los criterios mencionados con la información proveniente del corpus documental nos permitió aislar grupos como los de las pipas de La Ciénaga, los vasos calceiformes de las tumbas de La Aguada, los ajuares funerarios de la localidad de Azampay, etc.

\section{Comentários finales}

Los resultados obtenidos a partir de la aplicación de la perspectiva comentada fueron de relevancia en la generación de hipótesis acerca de conductas puestas en marcha en la manufactura de este tipo particular de cerámica para el NOA. En el caso específico de la porciones que representan a las entidades culturales Ciénaga y Aguada de la Colección estas modalidades particulares de agrupación permitieron identificar las siguientes problemáticas:

- detección de semejanzas a nivel tecnológico y decorativo entre los ajuares de ciertas unidades de entierro de un mismo cementerio o cementerios contiguos, que podrían estar indicando la existencia de especialistas en la manufactura de esta clase particular de cerámica;

- presencia reiterada de piezas semejantes entre sí, a nivel de tamaño, forma y decoración, en una misma unidad de entierro,

- detección de antiguas prácticas de restauración en objetos cerámicos en cantidades estadísticamente significativas (Balesta y Zagorodny m.s);

- evidencia de problemas constructivos para la confección de contenedores funerarios Ciénaga con respecto al resto de los objetos asociados por unidad de entierro, lo que permitió plantear la hipótesis de un mayor dominio técnico en la manufactura de piezas de menor tamaño; ya que en las piezas grandes se observa con cierta recurrencia la presencia de estallidos en las superficies y mayor profusión de agujeros de reparación (ibíd);

- registro de distintas modalidades de expresión para la figura del camélido en la entidad cultural Ciénaga (Balesta 1997);

- detección de imágenes de camélidos en frisos que hasta el momento se habían clasificado como "geométricos" (ibíd).

En general, los subconjuntos generados a partir de piezas completas no pueden aislarse fisicamente, ya que esto produciría interferencias en los modos de clasificación y catalogación propios de 
cada institución. Debido a esto, se recomienda registrar la información obtenida, en libretas específicas confeccionadas ad-hoc complementadas con registro gráfico y fotográfico del material en cuestión para una posterior informatización de los datos obtenidos. En el caso que nos ocupa la información resultante fue volcada en una base de datos de los cementerios de La Ciénaga y La Aguada confeccionada bajo el programa Dbase III.

Los subconjuntos surgidos a partir del material fragmentario sí han podido constituir agrupamientos separados, constituyendo por ejemplo: el subconjunto de las asas, el de los bordes, el de las bases, etc. que expresan el rango de variación de las técnicas involucradas en su manufactura. También la realización de estudios tecnológicos de carácter microscópico ha permitido la confección de una ceramoteca compuesta por tiestos testigos, dibujos de los mismos, desagregación de parte de los tiestos y sus cortes delgados y fichas de registro que reflejan los resultados para cada ítem.

Como especialistas en ceramología, el estudio de esta Colección nos ha permitido:

- confeccionar grupos de referencia que pueden ser contrastados con otros materiales arqueoló- gicos provenientes de corpus conmensurables con aquéllos;

- recuperar las operaciones cognitivas involucradas en la producción de la alfarería funeraria del NOA;

- formular hipótesis vinculadas con la conducta funeraria de aquéllos pueblos y

- formar recursos humanos a través del entrenamiento de alumnos y jóvenes investigadores transformando de este modo el depósito de un museo en un espacio de investigación y docencia.

Del mismo modo que estos materiales sirvieron durante décadas para inspirar trabajos por parte de numerosos e importantes investigadores, hoy en día siguen generando fuentes de conocimiento a través de la posibilidad de aplicar nuevas técnicas de análisis. Por otra parte, queremos no solamente revalorizar la información proveniente del estudio de colecciones museológicas, sino también contribuir a derribar la falsa dicotomía que en muchos casos se ha promovido entre el trabajo de campo y el trabajo con colecciones; ya que éstas nos proveen de un marco de contrastación invalorable en función de la posibilidad que ofrecen para comparar sus materiales con aquéllos provenientes de excavaciones actuales.

BALESTA, B; ZAGORODNY, N. Contribution to the archaeological knowledge through the analysis of museological collections. Rev. do Museu de Arqueologia e Etnologia, São Paulo, $8: 235-240,1998$

ABSTRACT: The present paper deals with the history and peculiarities of Benjamín Muñiz Barreto Collection. This collection is located in La Plata Museum (Argentina). The authors' aim consists in reassessing the value of the information proceeding from the Museum's collections. The methodology applied in this paper rests on a cognitivist framework and sets up on technological and simbolic approaches.

UNITERMS: Reassessment of the value - Collection - Museum - Cognitivism. 
BALESTA, B: ZAGORODNY, N. Contribución al conocimiento arqueológico a través del análisis de colecciones museológicas. Rev. do Museu de Arqueologia e Etnologia, São Paulo, 8: 235-240, 1998.

\section{Bibliografía}

BALESTA, B.

1994 La cerámica funeraria de La Ciénaga: hacia un análisis comunicacional. Actas del $X$ Congreso Nacional de Arqueología. San Rafael. Mendoza.

1997 La representación del camélido en La Ciénaga. Actas del XI Congreso Peruano del Hombre y la Cultura Andina "Augusto Cardich". Huánuco. Perú.

BALESTA, B.; ZAGORODNY, N.

1996 La restauración alfarera en la funebria arqueológica, m. s.

1997 La Loma de los Antiguos. Azampay (Depto.Belén. Catamarca). Resúmenes del XII Congreso Nacional de Arqueología. La Plata.

\section{DEBENEDETTI, $\mathrm{S}$}

1931 L'Ancienne Civilisation des Barreales du NorOuest d'Argentine. Ars Americana, Vol. II, París.

GONZÁLEZ, A. R.; COWGILL, G.

1975 Cronología Arqueológica del Valle de Hualfín. Pcia. de Catamarca, Argentina. Obtenida me- diante el uso de computadoras. Actas del I Congreso Nacional de Arqueología Argentina. Rosario.

MÁRQUEZ MIRANDA, F.

1946 Los Diaguitas. Revista del Museo de La Plata. (NS) III, La Plata.

\section{WEISSER, W.}

s/f Libretas de campo y diarios de viajes de las expediciones Muñiz Barreto. Departamento Científico Arqueología. Museo de La Plata, m.s.

\section{ZAGORODNY, N.; BALESTA, B}

1997 Revalorización del estudio de colecciones museológicas. Museológicas VI. Revista de la Universidad del Tolima. Ibagué. Colombia.

1997 La construcción de grupos de referencia como herramienta en la investigación ceramológica. Resúmenes del XII Congreso Nacional de Arqueología Argentina. La Plata.

Recebido para publicação em 8 de abril de 1998. 